\title{
SuperLib Project: Advanced Dual-Cell Battery Concept for Battery Electric Vehicles
}

\author{
N. Omar ${ }^{1,2}$, Th. Coosemans ${ }^{1}$, J. Martin ${ }^{3}$, V. Sauvant-Moynot ${ }^{3}$, J. Salminen ${ }^{4}$, B. Kortschak ${ }^{5}$, V. \\ Hennige $^{5}$, J. Van Mierlo ${ }^{1}$, P. Van den Bossche ${ }^{2}$, \\ ${ }^{1}$ Vrije Universiteit Brussel, Pleinlaan 2,1050,Brussels, Belgium,noshomar@vub.ac.be \\ ${ }^{2}$ Erasmus University College Brussels, Nijverheidskaai 170, 1070, Brussels, Belgium \\ ${ }^{3}$ IFP Energies Nouvelles, Rond-point de l'échangeur de Solaize - BP 3,69300, Solaize, France, joseph.martin@ifpen.fr \\ ${ }^{4}$ European Batteries, Karapellontie 11,02610,Espoo, Finland, justin.salminen@europeanbatteries.com \\ ${ }^{5}$ AVL List GMBH, Hans-List Platz 1,8020,Graz, Austria,volker.hennige@avl.com
}

\begin{abstract}
This paper describes the Advanced Dual-Cell Battery Concept for Battery Electric Vehicles in the framework of the European Seventh Framework Programme (FP7). The project investigates a well promising new energy concept, whereby high energy and high power dimensioned batteries are combined on cell level. The proposed methodology should allow to extend the battery life cycle by imposing peak power at the high power cell and supplying energy by the main energy source: high energy cells. Moreover, the new concept will assist to prolong the range of an e-car compared to conventional battery electric vehicles with high energy cells. Therefore, new advanced battery models, including adequate estimation techniques for battery model parameters, state of charge and state of health, will be developed at the Vrije Universiteit Brussel and IFP Energies Nouvelles. Then, from the point of view of the electronic architecture, the energy transfer between high energy and high power cells and balancing system from the other side will be carried out by Valeo and IFP Energies Nouvelles. Finally, this innovative concept will be validated by VDL, Volvo, CRF, European Batteries, and BOSCH companies.
\end{abstract}

Keywords: Thermal management, simulation, lithium battery, HEV, BEV

\section{Introduction}

Since the beginning of the automobile era, the internal combustion engine (ICE) has been used for vehicular propulsion. In addition, motor vehicles powered by the ICE are significant contributors to air pollutants and greenhouse gases linked to global climate change [1,2]. As the global economy begins to strain under the pressure of rising petroleum prices and environmental concerns, research has spurred the development of various types of clean energy transportation systems such as Hybrid Electric Vehicles (HEVs), Battery Electric Vehicles (BEVs) and Plug-in Hybrid Electric Vehicles (PHEVs) $[3,4]$. But the establishment of the energy storage technology which can support the output power during acceleration, the efficient use of the regenerative energy and considerable life cycle are the critical aspects and no current battery technology can meet these often concurrent objectives [4-7].

In the last decennium Electric Double-Layer Capacitors have been considered as a possible 
solution in BEVs and HEVs due to their excellent properties in the terms of power density and life cycle. However, the implementation of such system with the associated DC-DC converter is still expensive due to the high cost of the power electronics system.

In order to overcome the limitations of the battery system in BEV applications, a new project, called SuperLib, has been launched in the framework of the European Seventh Framework Programme (FP7) addressing the combination of high energy and high power Liion batteries for the enhancement of the overall system performance, for the improvement of the battery lifetime, the reliability and the cost/performance ratio of the battery system [8].

\section{Project targets}

In BEVs and PHEVs, the battery system can be considered as a key component. The battery in these applications is designed as high energy rather than higher power. The energy content in large full BEVs is in the range of $15-25 \mathrm{kWh}$. However, these battery systems should have good power capabilities (up to $150 \mathrm{~kW}$ ) during acceleration and braking events. According to the United States Advanced Consortium targets, the energy density of the battery pack for PHEVs should be in the range of $140 \mathrm{Wh} / \mathrm{kg}$ and 300 $\mathrm{W} / \mathrm{kg}$, whileas the life cycle of the battery pack should be about 5000 cycles ( $70 \%$ DoD). Here, it should be noted that these objectives are still ambitious for commercial lithium-ion batteries. Especially, at pack level, the energy density is much lower due to the packing, interconnections, mechanical reinforcement at cell level, heating and cooling. Thus, there is a need for new requirements for BEVs and PHEVs based on realistic and feasible targets. In the framework of this project, a number of objectives have been defined (see Table 1).

\begin{tabular}{|l|c|c|}
\hline & SuperLib & USABC \\
\hline Energy density (Wh/kg) & $>75$ & 140 \\
\hline $\begin{array}{l}\text { Peak discharge Power } \\
(\mathrm{kW}), 10 \text { sec pulse }\end{array}$ & 75 & 38 \\
\hline $\begin{array}{l}\text { Peak charge power (kW), } \\
10 \text { sec pulse }\end{array}$ & 50 & - \\
\hline Useable energy (kWh) & 15 & 12 \\
\hline Self-discharge (\%/month) & $<5$ & - \\
\hline Nominal voltage (V) & 300 & 300 \\
\hline Life cycle (x\% DoD) & $\begin{array}{c}3000 \\
(90)\end{array}$ & $\begin{array}{c}5000 \\
(70)\end{array}$ \\
\hline Battery mass (kg) & 250 & 120 \\
\hline
\end{tabular}

Table 1. Comparison between SuperLib and USABC objectives

As we observe in Table 1, the state of charge swing during one cycle is extended from $70 \%$ for USABC to 90 for SuperLib. This issue can only be achieved by using a battery system, which is both able to provide peak power and to have high energy content. In order to accelerate the penetration of BEVs and PHEVs into the market, the battery system should have a lifetime above 3000 cycles, not be expensive neither heavy.

In order to achieve the above mentioned objectives, a number of European research institutes and industrial stakeholders are involved in this project. Vrije Universiteit Brussel, which has a strong expertise in the field of modelling and estimation techniques for various rechargeable energy storage systems, together with IFPEN and Fraunhofer, will transfer the required scientific knowledge to the industrial oriented partners such as Volvo, CRF, AVL, BOSCH, European Batteries and Valeo.

\subsection{Battery performances}

In order to guarantee the above specified objectives, an advanced battery is required. In this consortium, European Batteries provides high quality $45 \mathrm{Ah}$ lithium iron phosphate based battery cells. With an energy density of $138 \mathrm{Wh} / \mathrm{kg}$, these batteries are optimized as high energy batteries. Moreover, these battery cells have good rate capabilities as it is presented in Figure 1. Independent of the imposed current, the obtained discharge capacity is almost $40 \mathrm{Ah}$. Then these cells will be combined with high power cells with a rated capacity of $15 \mathrm{Ah}$.



Figure 1. Battery rate capabilities

\subsection{Battery models}

In battery management systems (BMS), the battery model can be considered as a key issue. In [9-13] a number of battery models have been proposed and 
implemented in BEVs and HEVs. However, these models are designed for well-specified systems and only have been optimized during short time durations. In BEVs, the accuracy of the battery model is of high importance during the long term, enabling to predict the battery performances, state of charge (SoC) and state of health $(\mathrm{SoH})$.

In the framework of this project, Vrije Universiteit Brussel will develop new second order electrical battery models, which will be compared and associated with the IFP Energies Nouvelles lumped-parameter thermal/electrical model. Furthermore, these models will be enhanced with adequate estimation techniques for SoC based on extended Kalman Filtering. While the parameterization of the battery electrical models will be made by means of new developed estimation techniques at the Vrije Universiteit Brussel, called Extended Levenberg Marquardt. An overview of the proposed enhanced battery model is illustrated in Figure 2.

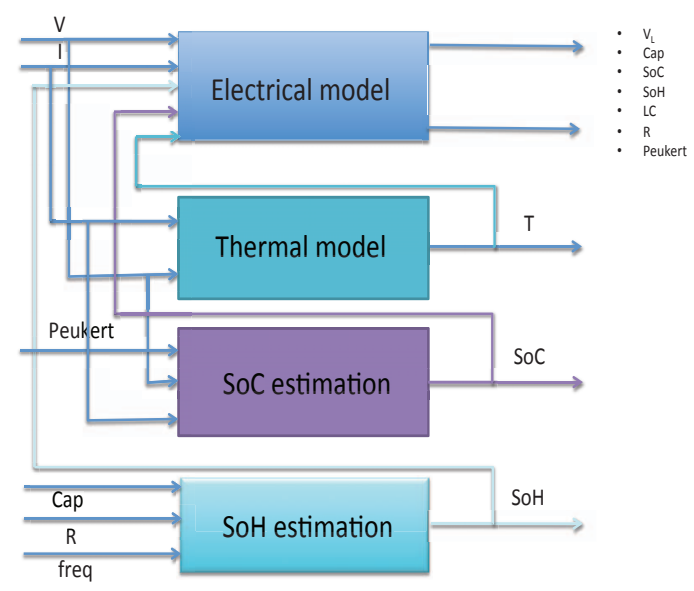

Figure 2. Enhanced battery model

\subsection{Thermal modeling}

The focus of the SuperLib projectlies on the association of HE-HP cells to achieve enhanced electrical performance. In order to prevent the thermal runaway of the batteries, an advanced thermal model will be developed at IFPEN [14, 15]. Moreover a multi-dimensional finite element thermal model will be developed, taking into account geometrical and thermal properties of Liion HE and HP cells as well as connectors and electronics. Moreover, a thermal/electrical lumped parameter model developed at IFPEN will be used as a building block in the multi- dimensional models for HP and HE cell: this coupling allows the simulation of thermal gradients within the cell. Thus, the multidimensional model will be used to simulate both internal gradients within cells and electrical components as well as outer and inter cells temperatures in the module architecture. Simulations will be performed to investigate the thermal behaviour of Li-ion cells and modules with respect to the cells number and geometry (see Figure 3). This approach will also be used to define the nature and flow of the cooling and adjust the inlet and outlet orifice of the flow circuit. Moreover, the temperature profiles in the gap between cells but also the thermal gradient inside cells will be considered to optimize thermal management strategies for PHEV and BEVs.



Figure 3. mesh of a given pack geometry and simulation of thermal distribution during an electrical test [15]

\subsection{Advanced battery management system}

Compared to EDLC, the combination of high power and high energy cells requires a well optimized balancing system between the cells within the stack as well as a system for the energy flow from one stack to another. In [8] a system is defined whereby each stack has its own balancing system. The energy flow between the stacks can be performed by a bi-directional DC-DC converter. However, this solution seems very expensive and heavy. A second solution which has been proposed by AVL and Valeo is the connection of both types of battery cells directly in parallel. Due to this integration, only one balancing system is necessary for the connected cells in series. However, by employing a heavy load profile to such topology, the high energy battery cells will suffer from the high peak current. This will decrease the lifetime of the high energy battery. Moreover, this approach needs high power electronic circuits, which is heavy and costly. A third approach which has been proposed in the framework of the project is based on the merits of the above mentioned 
systems, which is presented by Figure 5. In the proposed system, there is a need for a new bidirectional DC-DC converter for the distribution of the load by the both energy sources. Here, it should be noted that the high energy battery stack will only be responsible for delivering the mean power, while the high power cells will guarantee the peak power.

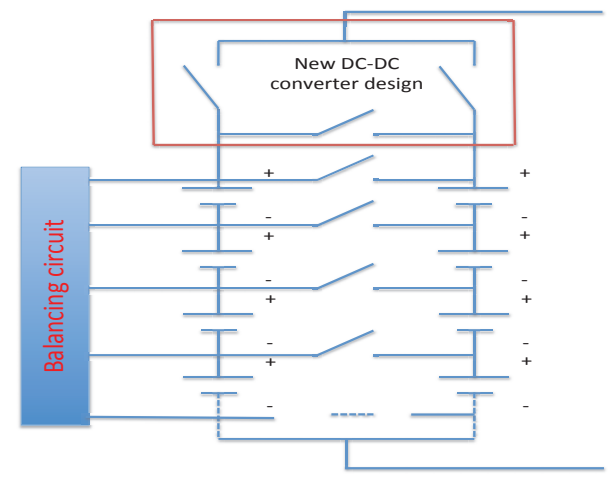

Figure 4. New DC-DC converter energy and current distribution (Source: AVL/Valeo)

\subsection{Advanced thermal sensor}

As reported by Omar et al, the temperature has a significantly impact on the battery performances [14]. Particularly, at low temperatures the battery performances reduce and at high temperatures the ageing phenomena in the battery accelerate. Moreover, the temperature distribution inside a battery is far from equal. For the proposed battery cells of European Batteries, where the terminals are located at one side, the temperature in the area between the two electrodes will be much higher. In order to prevent high local temperatures, an advanced thermal sensor as presented in Figure 5 into the pouch cells will be developed by Fraunhofer Institute in Germany. Furthermore such sensor allows to improve the performances of the BMS through accurate estimation of $\mathrm{SoC}$ and $\mathrm{SoH}$ on cell level. As mentioned above, these two parameters are strongly dependent on temperature.

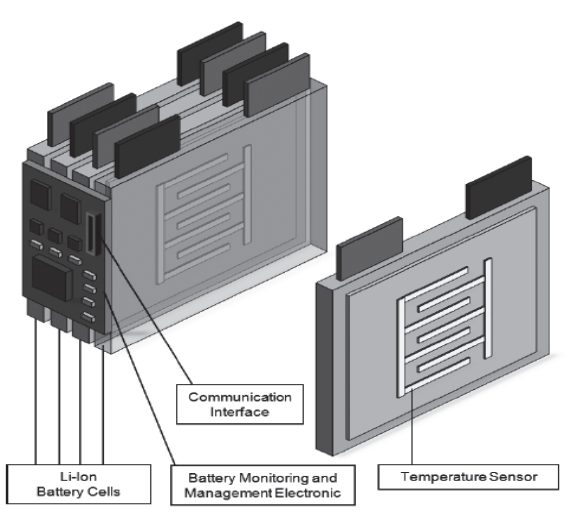

Figure 5. Integrated thermal sensor for pouch battery cells

\section{Program development}

The testing experiments have been started on cells since November 2011, using electric benches, climatic chambers and impedance meters from both VUB and IFPEN facilities. First results and model developments will be discussed soon.

Benefits of the program among others will be the crossing of methods in the fields of cell testing and modelling, and the fruitful comparison of different estimation strategies among the partners.

\section{Acknowledgments}

On behalf of all partners in the project, the authors would like to express their gratitude to the European Commission for the financial support of the project.

\section{References}

[1] J. Van Mierlo, G. Maggetto, E. Van De Burgwal, R. Gense, Driving style and traffic measures influences vehicle emissions and fuel consumption, in Proceedings of the Institution of Mechanical Engineers, Part D, Journal of automobile engineering, Vol. 218, No. 1, 2003, PP: 43-50

[2] J. Van Mierlo, G. Maggetto, et al., Comparison of the environmental damage caused by vehicles with different alternative fuels and drive trains in a Brussels context, in: Proceedings on the Institution of Mechanical Engineers, Part D, Journal of automobile engineering, Vol. 217, No. 7, 2003, PP: 583-593

[3] J. Axsen, Burke, K. Kurani, Batteries for Plugin Hybrid Electric Vehicles (PHEVS): Goals and State of the Technology, May, 2008

[4] N. Omar, B. Verbrugge, P. Van den Bossche, J. Van Mierlo, Power and Life Enhancement 
of Battery-Electrical Double Layer Capacitor for Hybrid Electric and ChargeDepleting Plug-in Vehicle Applications, Journal of the Electrochimica, March, 2010

[5] P. Van den Bossche, F. Vergels, J. Van Mierlo, J. Matheys, W. Van Autenboer, SUBAT: an assessment of sustainable battery technology, Journal of Power Sources, Vol. 162, No. 2, 2006, PP: 913 919

[6] J. Axsen, K. S. Kurani, A. Burke, Are batteries ready for plug-in hybrid buyers, Journal of Transport Policy, Vol. 17, Feb. 2010, pp: 173-180

[7] N. Omar, M. Daowd, B. Verbrugge, G. Mulder, P. Van den Bossche, J. Van Mierlo, M. Dhaens, S. Pauwels, F. Leemans, Assessment of Performance Characteristics of Lithium-Ion Batteries for PHEV Vehicles Applications Based on a Newly Test Methodology, The 25th World Battery, Hybrid and Fuel Cell Electric Vehicle Symposium, November 5 9, 2010, Shenzhen, China

[8] http://www.superlib.eu/, access on $25-01$ 2012

[9] A. Jossen, Fundamentals of battery dynamics, Journal of Power Sources, PP: 530-538, 2006

[10] L. Ménard, G. Fontès, S. Astier, Dynamic energy model of a lithium battery, Journal of Mathematics and Computers in Simulation, Vol. 81, PP: 327-339, 2010

[12] Sh. Santhanagopalan, Q. Guo, P. Ramadass, Review of models for predicting the cycling performance of lithium ion batteries, Journal of Power Sources, Vol. 156, PP: 620-628, 2006

[13] D. Baert, A. Vervaet, Lead-acid battery model for the derivation of Peukert's law, Journal of Electrochimica Acta, Vol. 44, PP: 3491-3504, 1999

[14] E. Prada, J.Bernard, R. Mingant, V. Sauvant-Moynot, Li-ion thermal issues and modelling in nominal and extreme operating conditions for HEV / PHEV's, VPPC 2010, Lille France, 1-3/09/2010

[15] E. Prada, J.Bernard, R. Mingant, V. Sauvant-Moynot, A physical approach to electrochemical storage system multi-scale modelling: electrochemical double layer capacitors (case study), EVS-25 Shenzhen, China, Nov. 5-9, 2010
[14] N. Omar, M. Daowd, G. Mulder, J.M. Timmermans, Th. Coosemans, P. Van den Bossche, J. Van Mierlo, S. Pauwels, Assessment of Performance of Lithium Iron Phosphate Oxide, Nickel Manganese Cobalt Oxide and Nickel Cobalt Aluminum Oxide Based cells for Using in Plug-in Battery Electric Vehicle Applications, IEEE Vehicle Power and Propulsion Conference (VPPC) 2011, ISBN-ISSN: 978-1-61284-246-2

\section{Authors}

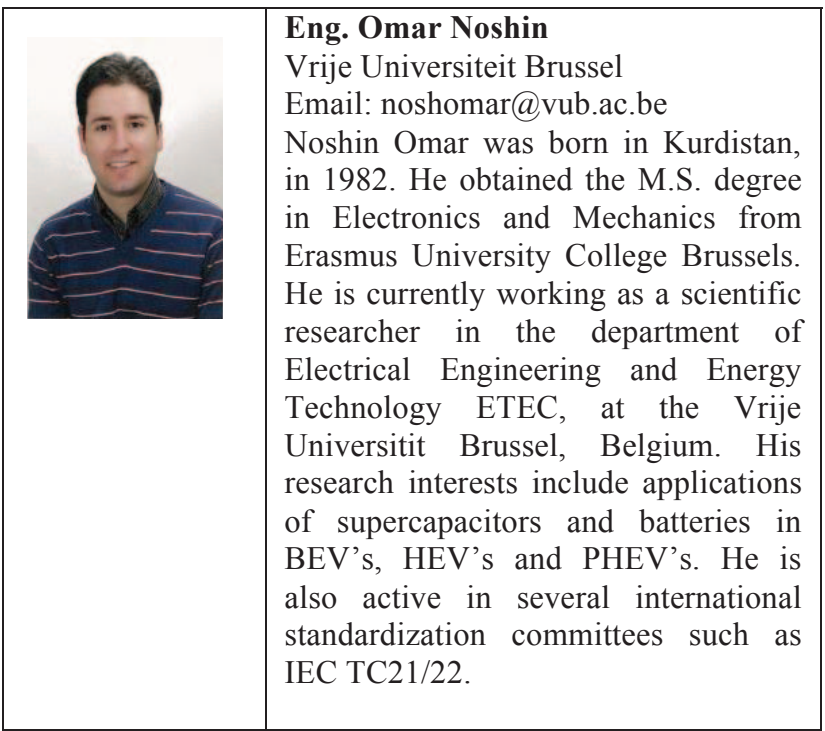

\begin{tabular}{|l|l|} 
Dr. ir. Thierry Coosemans \\
Vrije Universiteit Brussel \\
Email: Thierry.coosemans@vub.ac.be \\
Thierry Coosemans obtained his PhD \\
in Engineering Sciences from Ghent \\
University in 2006. After several years \\
in the industry, he now became a \\
member of the ETEC research team on \\
transport technology at the VUB. His \\
research topics include the \\
assessment of HEV propulsion \\
systems.
\end{tabular}

\begin{tabular}{|l|l|} 
Ing. Martin Joseph \\
IFP Energies nouvelles \\
Joseph.martin@ifpen.fr \\
Joined the Materials Department of \\
IFP Energies nouvelles in 1987 with \\
an Engineering degree of the National \\
Institute of Applied Sciences of Lyon \\
(INSA) joined the "battery" activity at \\
IFP Energies nouvelles in 2008 as \\
manager of the batteries tests benches
\end{tabular}






